\title{
BMJ Open Effectiveness of an improvement programme to prevent interruptions during medication administration in a paediatric hospital: a preintervention- postintervention study
}

Immacolata Dall'Oglio, ${ }^{1}$ Martina Fiori, ${ }^{1}$ Vincenzo Di Ciommo, ${ }^{2}$ Emanuela Tiozzo, ${ }^{1}$ Rachele Mascolo, ${ }^{1}$ Natalia Bianchi, ${ }^{3}$ Marta Luisa Ciofi Degli Atti, ${ }^{2}$ Antonella Ferracci, ${ }^{4}$ Orsola Gawronski, ${ }^{1}$ Manuel Pomponi, ${ }^{5}$ Massimiliano Raponi, ${ }^{6}$ Alert System Study Group

To cite: Dall'Oglio I, Fiori M, Di Ciommo V, et al. Effectiveness of an improvement programme to prevent interruptions during medication administration in a paediatric hospital: a preinterventionpostintervention study. BMJ Open 2017;7:e013285. doi:10.1136/bmjopen-2016013285

- Prepublication history and additional material is available. To view please visit the journal (http://dx.doi.org/ 10.1136/bmjopen-2016013285).

Received 6 July 2016 Revised 8 September 2016 Accepted 14 September 2016

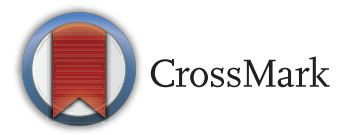

For numbered affiliations see end of article.

Correspondence to Dr Immacolata Dall'Oglio; immacolata.dalloglio@opbg. net

\section{ABSTRACT}

Objective: To assess the effectiveness of an improvement programme to reduce the number of interruptions during the medication administration process in a paediatric hospital.

Design and methods: A prestudy-post study design was used to monitor nursing interruptions during medication cycles in a paediatric hospital. Interruptions were reported on an observation sheet (MADOS-P) adapted to the paediatric context.

Setting: A 600-bed tertiary paediatric research hospital in Italy.

Intervention: The interventions included a yellow sash worn by nurses during medication cycles, a yellow-taped floor area indicating the 'No interruption area', visual notices in the medication areas, education sessions for healthcare providers and families, patient and parent information material.

Results: 225 medication cycles were observed before the intervention (T0) and 261 after the intervention (T1). The median of interruptions occurring in each cycle decreased significantly from baseline to postintervention ( 8.0 vs $2.0, p=0.002$ ), as the rate ratios (interruptions/patient post-pre ratio: 0.34 ; interruptions/medication post-pre ratio: 0.37 ; interruptions/hour of medication cycle post-pre ratio: $0.53, p<0.001)$. During preintervention, the main causes of interruptions were 'other patients' $(19.9 \%)$, 'other nurses' (17.2\%) and 'conversation' (15.7\%); during postintervention, they were 'other nurses' (26.1\%), 'conversation' (18.2\%) and 'other patients' $(17.4 \%)$.

Conclusions: This bundle of interventions proved to be an effective improvement programme to prevent interruptions during medication administration in a paediatric context.

\section{INTRODUCTION}

The medication process in the hospital setting consists of five phases: medication

\section{Strengths and limitations of this study}

- This study shows the effectiveness of bundled interventions to reduce interruption during the medication administration process in a paediatric hospital.

- Compared with other studies, this study included a significant number of medication cycles $(n=486)$ and patients $(n=1391)$.

- This study focused on education sessions for healthcare providers, parents and patients.

- Interruptions were not classified into avoidable or not, or necessary or not.

- Direct observation could have modified participants' behaviour and confounded the real effects of our intervention on participants.

prescription, preparation, dispensation, administration and monitorisation. Every stage of this complex process presents risk factors for medication errors. ${ }^{1-3}$

Considering the paediatric population, the potential adverse drug events rate has been suggested to be three times higher compared with adults and significantly higher in neonatal intensive care units (NICU). ${ }^{4}$ This is due to weight-based dosing necessary for almost all medications; all children, especially newborns, have a lower coping capacity than adults when medication errors occur. ${ }^{4}$ Furthermore, in paediatric patients, medication preparation is more complex. It usually requires detailed calculations and manipulations of adult preparations. ${ }^{46}$

Nursing care processes have an impact on medication preparation and administration errors since nurses administer most of the medications. ${ }^{7}$ According to several authors, interruptions during medication administration are 
among the main causes of medication errors. ${ }^{7-10}$ In a large observational study, Westbrook et $a l^{11}$ reported that every interruption is significantly associated with a $12.7 \%$ increase in clinical errors. However, evidence of an association between interruptions and errors in medication administration is still limited and more rigorous studies are needed. ${ }^{12}$ A recent Italian study performed on five surgical wards in five general hospitals reported that medication administration was the most frequently interrupted task. ${ }^{13}$

Several studies have also identified the causes of interruptions during medication administration in hospital wards such as disruptions from other health personnel, conversations among nurses and missing medications on the trolley or in the ward. ${ }^{13-16}$ The organisation of the medication administration process, healthcare providers' demands on nursing staff and the work environment are factors associated with medication administration interruptions. ${ }^{13-16}$ These findings have also been confirmed in paediatric settings. For instance, McGillis Hall $e t a l^{17}$ showed that factors in the work environment itself accounted for one-third $(32.7 \%)$ of the interruptions. The results of a survey on medication administration practices revealed that $86 \%$ of the children's nurses considered interruptions as a cause of medication errors. $^{6}$

Few studies investigated interventions to reduce interruptions to improve medication administration safety in the adult hospital setting. ${ }^{14} \quad 15 \quad 18-23$ As reported by Raban and Westbrook, ${ }^{24}$ these studies have been underpowered and their level of evidence is weak. To date, no studies in the paediatric setting have been reported. Therefore, it is important to analyse if interventions performed in adult hospital settings aimed at reducing interruptions during medication administration may be effective also in children's care. The paediatric setting has different peculiarities, such as the presence of parents at the bedside and children's compliance to any hospital interventions depends on different factors, such as age or previous experiences. Both could influence the effectiveness of the interventions conducted in the adult setting.

Failure Mode, Effects and Criticality Analysis (FMECA) on the medication process was performed in 2010-2011 in the Onco-Haematology department of the paediatric hospital where the present study was conducted.$^{25}$ A potential risk of errors due to interruptions was identified but not reported in the cited article and bundled interventions were implemented to reduce medication administration interruptions. Therefore, the evidence regarding the implementation of bundled interventions to reduce medication administration interruptions appears weak and unexplored in paediatric settings.

The aim of the present study is to assess the effectiveness of an improvement programme to reduce interruptions during medication preparation and administration in a paediatric hospital.
METHODS

\section{Study design}

A quasi-experimental study with a pre-post design and no control was performed. The study was conducted from January to July 2013. Medication cycles were observed before and after the implementation of an improvement programme to reduce interruptions. A medication cycle is the process of a nurse preparing and administering medications to assigned patients at a scheduled time. The medication cycle ends when the nurse has administered all the prescribed medications to all the assigned patients. ${ }^{26}$

In January and February 2013, preintervention (T0) baseline observation was performed by research nurses to measure the frequency and causes of interruptions during medication cycles in daily practice. During March and April 2013, no data were collected to run the implementation effectively in all wards. Finally, postintervention (T1) measurements were performed in May and July 2013.

\section{Ethical considerations}

Approval was obtained from the Hospital Ethical Review Board. The nurses invited to be involved in medication administration and observed by researchers were informed beforehand about the study and agreed to participate. They completed and signed the consent form. This specified that nurses must respect the behaviours requested in the project but were not obliged to be involved in the observation for the research. None of the nurses refused. The identity of the observed nurses was kept anonymous.

\section{Setting and sample}

The study was conducted within the scope of an improvement programme aimed at reducing interruptions during medication preparation and administration in a 600-bed tertiary paediatric research hospital in Italy. The improvement programme was implemented in all the hospital wards after a brief pilot phase in the Paediatric Department.

The medication cycle observations were performed in eight wards considered representative of the whole hospital. Selected wards were (table 1): two medical-surgical wards admitting also children with complex needs (eg, renal or neurosurgery patients, patients postorgan transplant), one cardiac surgery step-down unit, two NICU and post-NICU (eg, very low birth weight children, infants with congenital anomalies) and three medical wards (eg, patients with cancer or patients after bone marrow transplant).

The nurse-to-patient ratio varies from 1:2 in the NICU, $1: 4$ in the post-NICU and cardiac surgery step-down unit to $1: 8$ in the other wards, depending on patient complexity. The preparation and administration of medication followed the same procedure in every ward. Medication preparation was performed by ward nurses except for chemotherapy medications that were 
Table 1 Number and per cent of medication cycles per unit preintervention and postintervention

\begin{tabular}{|c|c|c|c|c|}
\hline \multirow[b]{2}{*}{ Units } & \multicolumn{2}{|l|}{ TO* } & \multicolumn{2}{|l|}{ T1† } \\
\hline & $\mathbf{n}$ & $\begin{array}{l}\text { Per } \\
\text { cent }\end{array}$ & $\mathbf{n}$ & $\begin{array}{l}\text { Per } \\
\text { cent }\end{array}$ \\
\hline $\begin{array}{l}\text { Cardiac surgery } \\
\text { step-down }\end{array}$ & 45 & 20.0 & 46 & 17.6 \\
\hline NICU & 36 & 16.0 & 48 & 18.4 \\
\hline Post-NICU & 17 & 7.6 & 13 & 5.0 \\
\hline Neurology & 34 & 15.1 & 35 & 13.4 \\
\hline Nephrology & 38 & 16.9 & 53 & 20.3 \\
\hline Onco-Haematology & 32 & 14.2 & 43 & 16.5 \\
\hline $\begin{array}{l}\text { Bone marrow } \\
\text { transplantation }\end{array}$ & 15 & 6.7 & 17 & 6.5 \\
\hline General paediatrics & 8 & 3.6 & 6 & 2.3 \\
\hline Total & 225 & 100.0 & 261 & 100.0 \\
\hline $\begin{array}{l}\text { *Preintervention. } \\
\text { †Postintervention. } \\
\ddagger \text { Neonatal intensive car }\end{array}$ & & & & \\
\hline
\end{tabular}

dispensed ready-to-use by the hospital pharmacy. All other medications on the ward were stored in dedicated closets. None of the wards included in the study had an automated/computerised medication dispensing system. The preparation took place at the patient's bedside, on a trolley (NICU and post-NICU) or in a dedicated medication room according to the hospital policy on medication management. The nurses followed the pharmacological prescription chart contained in the patient's health record, prepared the prescribed dosage at the right time, labelled the medication with the patient's name, the date of birth, medication name, dosage and abbreviation of the nurse's name. For the infusion therapy, nurses also recorded the time of preparation. Nurses administered the medication at the bedside and recorded the administration on the medication chart. As per hospital policy, no medication self-management is allowed by patients or caregivers.

The participants of the present study were the nurses caring for patients in the involved wards. Throughout the 7-month period of the study, the nursing staff remained stable on the whole.

Data were collected only during daytime and weekdays. Medication cycles were observed by six research nurses who also verified that the participating nurses complied with the planned intervention.

\section{Interventions}

The bundled interventions were developed, evaluated and implemented according to the MRC guidelines. ${ }^{27}$ Before starting the study, the programme was presented to the ward nurse managers of the hospital and included the following: (1) A yellow sash worn by the nurses responsible for the medication round bearing the words: 'Do not disturb: medication round in progress'. (2) A yellow-taped floor area around the medication trolley or in front of the door of the medication preparation room defining the 'No interruption area'. (3) A visual sign with the message 'Please, do not disturb! Medication preparation in progress. Call the nurse with the yellow sash for urgent issues only' indicating that the nurse was engaged in medication administration. This 'alert' sign was put on the trolley or hung on the door of the medication preparation room during the medication cycle. According to the Medical Direction, the yellow-coloured signs were preferred to the red of other studies, ${ }^{15} 182228$ to avoid confusion with the red-coloured signals already present in the hospital indicating urgency or danger situations (eg, fire alarm). Furthermore, the yellow colour is generally used in Italy to indicate a protective zone (eg, for privacy). (4) Information sessions with healthcare providers to describe the programme objectives, intervention, the timeline and the evaluation process. Ward nurses were provided with the alert material and were instructed on its use. The participating nurses were recommended to not prepare and administer medications all together at the same time, so that at least one nurse could attend to patients' needs or deal with other healthcare requests. (5) Education for patients and families with leaflets and posters about the 'Alert' signs. They were invited to collaborate and to not interrupt the nurses during medication preparation and administration unless there was an urgency. Leaflets were distributed to parents and children >aged 7 years on admission to the ward. A brief educational session was also provided by the nurse in charge. All the education interventions were regularly documented on the patient's clinical record.

\section{Data collection procedures and tools}

Data on the frequency and causes of interruptions during medication cycles were collected by research nurses through direct overt non-participant observation of the nurses responsible for medication preparation and administration.

An interruption can be defined as 'a break in continuity of complete focus on the task of preparing medication'. An interruption could be a verbal or non-verbal cue from another individual prompting the nurse to give a verbal or non-verbal response. ${ }^{23}$

For the purpose of this study, the operational definitions were described in the data collection sheet (see online supplementary appendix 1, Mados-P, page 2) where some events are classified as 'interruption only' or 'distraction only', or both. Therefore, for simplicity, interruptions and distractions were called 'interruptions'. Interruptions by patients or caregivers during the medication administration process were not counted because they were considered appropriate in this phase (eg, questions regarding the medication). Similarly, the interruptions concerning the double-check procedure required for some medications (eg, electrolytes and high-risk medication) were not counted.

The research nurses did not work in the wards that were included in the study. They were informed 
beforehand about the intervention, the data collection instrument and procedures through two educational sessions. At each observation session, the research nurse oversaw one or two nurses throughout the medication cycle of all their patients, from the beginning (medication preparation) to the end (medication registration on the medical record).

The validated 'Medication Administration Observation Sheet' (MADOS) developed by Pape, ${ }^{14}$ and adapted to the paediatric setting was used for data collection. This Italian paediatric version (MADOS-P) was developed with the author's authorisation by means of a forward and backward translation process. An expert group of nurses reviewed the process by supervising the modification of certain items regarding the causes of interruption on the original observation sheet and the introduction of new items related to the paediatric setting. Furthermore, the observation sheet was integrated with the demographic data form used by Pape, ${ }^{14}$ and completed with additional information, such as the ward where the observation was performed, the number of patients receiving medications and the number and route of medications that were administered. During data collection, research nurses recorded all the variables on the MADOS-P, start-end time, duration of the medication cycle and the number and causes of interruptions. Nurses were aware that the interruptions during medication administration were being measured.

Inter-rater reliability was tested by observing 25 medication cycles, which were simultaneously rated by 2 research nurses. The results of the 2 ratings were compared and only 9 discrepancies occurred out of a total of 450 items documented on the Mados-P for all the observations performed (25 observed medication cycles times 18 variables contained in the sheet). The overall agreement was therefore $98 \%$. These observations were a subset of the total of the observed medication cycles.

Data related to errors in the medication administration process are routinely monitored by a voluntary incident reporting system. This system includes: adverse events, defined as unintentional and undesirable events that may cause patient harm; near misses, defined as errors that do not result in injury; sentinel events, defined as an unexpected occurrence involving death or serious physical harm. Data referred to the period of preobservation or postobservation in the units involved in this study were considered. Rates were calculated as number of reported events/1000 inpatient days in the two periods of the study.

After the programme was run, a debriefing meeting was held with the nurses of each ward involved in the study. The purpose was to explore nurses' perceptions of preparation and administration of medication safety in their wards, the perceived intervention efficacy in reducing interruptions as well as the patients', caregivers' and healthcare providers' perceived compliance with the interventions.

\section{Statistical analysis}

Data were described as means, medians and ranges because their distribution was non-normal and inferences were performed with non-parametric tests (ie, Mann-Whitney rank test). Fisher's exact test and $\chi^{2}$ test were used, as required, to compare the proportions.

Rate ratios (RRs) were calculated as in incidence density studies for pertinent denominators to adjust the different absolute numbers of the principal variables, such as interruption, patient and medication.

To explore the interruption sources, the original 18 causes were collapsed to 11 categories. In this way, the results are also easier to understand (see online supplementary appendix 2, table 1). The Statistical Package for Social Sciences (SPSS V.15) was used. A p value of $<0.05$ was considered statistically significant.

\section{RESULTS}

\section{Setting, sample and medication cycles}

A total of 486 medication cycles were observed during preintervention (T0) and postintervention (T1) (225 vs 261) (table 1). The vast majority of the medication cycles were carried out by female nurses (419 out of 486; $86.2 \%)$. About one-third of the cycles $(37.7 \%)$ were carried out by nurses with $\leq 5$ years of working experience, with no significant difference between $\mathrm{T} 0$ and $\mathrm{T} 1$ (37.1\% vs $38.3 \%)$. All the participating nurses complied with the proposed behaviours (eg, wearing the yellow sash or hanging the poster). A total of 150 hours and 8 min of observation were performed during preintervention, and 97 hours and 9 min during postintervention.

The number of patients for each medication cycle was significantly higher in T0 than in T1 (median: 3 vs 2; $\mathrm{p}=0.022$ ). Similarly, a significant decrease in the number of medications prepared and administered during each cycle occurred between T0 and T1 (median: 9 vs 5; $\mathrm{p}<0.001)$. Most of the medications were administered orally and intravenously (table 2 ).

\begin{tabular}{|c|c|c|c|c|}
\hline & \multicolumn{2}{|l|}{ TO* } & \multicolumn{2}{|l|}{ T1† } \\
\hline & $\mathbf{n}$ & $\begin{array}{l}\text { Per } \\
\text { cent }\end{array}$ & $\mathbf{n}$ & $\begin{array}{l}\text { Per } \\
\text { cent }\end{array}$ \\
\hline Patients (tot.) & 690 & & 701 & \\
\hline \multicolumn{5}{|l|}{ Medications } \\
\hline $\begin{array}{l}\text { Intravenous } \\
\text { medications }\end{array}$ & 1073 & 44.1 & 948 & 42.3 \\
\hline Oral medications & 1288 & 53.0 & 1255 & 56.0 \\
\hline Aerosol medications & 34 & 1.4 & 7 & 0.3 \\
\hline Other medications & 37 & 1.5 & 32 & 1.4 \\
\hline Medications (tot.) & 2432 & 100.0 & 2242 & 100.0 \\
\hline
\end{tabular}


Table 3 Interruptions rate/ratios post/pretest

\begin{tabular}{|c|c|c|c|c|}
\hline & TO* & T1† & Rate ratio $\mathrm{T} 1-\mathrm{T0}$ & p Valueł \\
\hline Interruptions/patient rate & 3.33 & 1.13 & 0.34 (95\% CL 0.31 to 0.38$)$ & $p<0.001$ \\
\hline Interruptions/medication rate & 0.94 & 0.35 & 0.37 (95\% CL 0.35 to 0.41$)$ & $p<0.001$ \\
\hline Interruptions/hour of medication cycle rate & 15.25 & 8.13 & 0.53 (95\% CL 0.49 to 0.58$)$ & $p<0.001$ \\
\hline
\end{tabular}

The length of the medication cycles significantly decreased after implementing the programme (median: 35 min $\mathrm{T} 0$ vs 20 min $\mathrm{T} 1$; $\mathrm{p}<0.001)$.

\section{Interruptions}

The total number of observed interruptions decreased from 2303 in T0 to 797 in T1. The RRs were calculated as in incidence density studies for pertinent denominators to adjust the different absolute numbers of the principal variables such as interruption, patient and medication.

Therefore, appropriate comparisons could be performed between the interruptions-to-patient ratios, the interruptions-to-medication ratios and the interruptions-to-hour of medication cycles in T0 and T1. This confirmed the significant $(p<0.001)$ decrease in the interruptions, despite the difference in the number of occasions (table 3).

The postintervention rate for interruptions-to-patient and interruptions-to-medication ratios was about onethird of the preintervention rate, while for the interruptions-to-hour of medication cycle ratio was slightly less than half.
After the implementation, the median of interruptions occurring in each cycle at T0 was significantly higher than at T1 (T0: 8.0, range $0-44$ vs T1: 2.0 range 0-22, $\mathrm{p}=0.002$ ). This decrease was observed in all the interruption categories, except for 'Emergency'.

The most significant decrease was observed in the following categories: 'Other patients', particularly for the interruptions caused by 'Patient's bell call' (T0: $n=203$; T1: $\mathrm{n}=9$ ) and 'Monitor' (T0: $\mathrm{n}=211 ; \mathrm{T} 1: \mathrm{n}=96)$; 'Parent/ Visitors' (T0: $\mathrm{n}=201$; T1: $\mathrm{n}=56$ ); 'Phone call' (T0: $\mathrm{n}=177$; T1: $\mathrm{n}=27$ ).

In postintervention, the main causes of interruption/ distraction remained 'Other nurse', 'Conversation' and 'Other patient'.

Figure 1 shows the interruptions-to-hour of medication cycle rates and significance compared between $\mathrm{T} 0$ and T1 for every source. Only the 'Emergency situation' and 'Prescription/Missing medication' categories did not show a significant rate decrease.

No variations in the rate of errors regarding preparation or administration of medications were recorded ( 5 cases $/ 6811$ inpatient-days pre vs $2 / 4018$ post; $\mathrm{p}=0.9$ ).

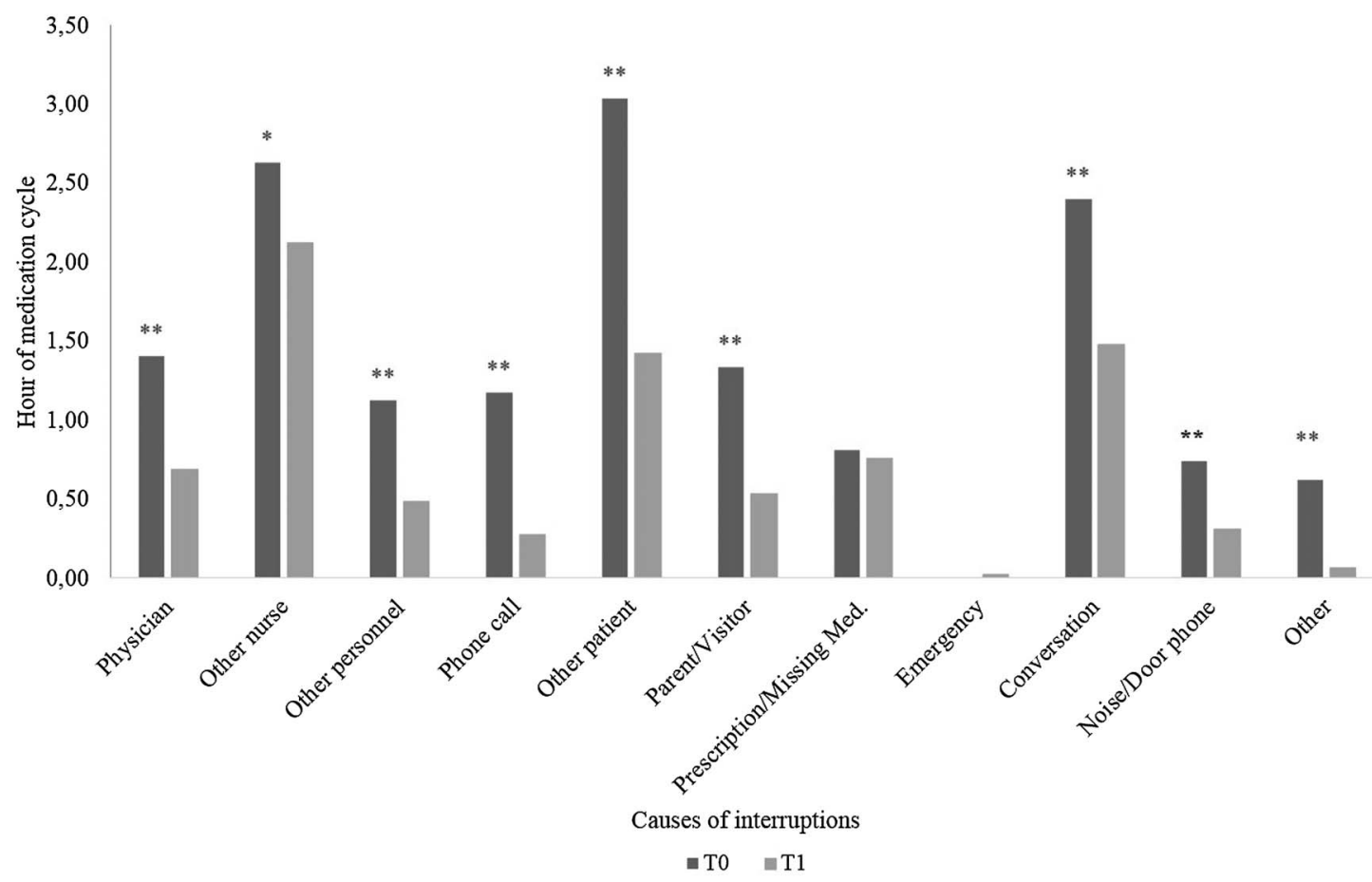

Significant difference T0 vs T1: ${ }^{*} \mathrm{p}<0.05 ;{ }^{*} \mathrm{p}<0.001$

Figure 1 Causes of interruption/hour of medication cycle preintervention and postintervention. 
During the debriefing meetings, nurses reported that the time required for medication administration was perceived to be less after the intervention. Nurses felt protected when wearing the yellow sash, especially from parents, and were more concentrated on what they had to do. The parents learnt to postpone their requests when they were not urgent or to call only the available nurses who were not wearing a sash.

\section{DISCUSSION}

An improvement programme was implemented in a paediatric hospital to reduce medication administration interruptions, which proved to be effective. A large number of patients receiving medication were observed. Similarly, in the multicentre study by Tomietto et $a l^{15}$ there were around 800 patients in $\mathrm{T} 0$ and $\mathrm{T} 1$, but much fewer in the study by Freeman $e t a l .^{21}$ In other studies, as reported by Raban and Westbrook, ${ }^{24}$ the number of patients was not described.

Likewise, the number of medications administered in this study was very high. Only the study by Kliger $e t a l^{22}$ involving 6 hospitals and 22 wards, investigated around 2200 medications administered at each step of the monitoring process. In other studies, the number of medications administered, when reported, was about 100-200 in preintervention or postintervention observation. ${ }^{19} 23$

In the present study, a significant decrease in interruptions was observed when the potential effects of the reduction in the numbers of patients, medications and medication cycle length were removed through the comparison of pertinent ratios. There was a decrease in most of the causes of interruption.

Other studies have shown similar results, ${ }^{18} 2329$ except for an Italian study that obtained the opposite result. In this case, the intervention consisted mainly in the red tabard for the nurses. ${ }^{15}$

The duration of the intervention effects was not monitored in our study. However, two studies that explored the duration of the effects found no decrease 6-12 months after the first evaluation. ${ }^{19} 29$

A reduction in the duration of the medication administration cycles was observed after the implementation of the programme as in previous research. ${ }^{18}{ }^{20}$ However, we cannot definitely say what was the cause or the effect of the concurrent reduction in the interruptions. On the other hand, we can state that, considering the indicator of interruptions/hour of medication cycle rate, there was a significant reduction. These findings were also confirmed by the nurses' perceptions reported during the debriefing meetings.

The greatest decrease in the causes of interruption concerned the category 'Other patient', 'Parent/Visitor' and 'Phone call'. This could be probably attributed to the effectiveness of the educational intervention directed to staff, patients and their families. These findings are only partially confirmed by a study conducted in a short-stay high-intensity unit. ${ }^{18}$ This paper showed a significant decrease in the average number of interruptions due to 'Other nurse' and 'Conversation' but not in those due to 'Other personnel', 'Other patient', 'Parent/Visitor' and 'Phone call'. Furthermore, the study by Relihan et $a l^{18}$ focused on education sessions regarding only healthcare professionals' behaviours related to the intervention. Instead, in our study, also patient and family education were emphasised.

Nevertheless, a weaker reduction was noted for the category 'Other nurse', probably indicating that interruptions due to issues relevant for nursing care are more difficult to prevent. These findings were similar to those obtained by Relihan $e t a l^{18}$ but differed from those obtained by Tomietto et al, ${ }^{15}$ that showed a significant increase for this cause, responsible for an overall rise in the interruption rate. Other authors reported a decrease in the number of interruptions but did not assess the statistical significance of the results. ${ }^{14} 2123$

The medication error event rates that occurred during the study period was low compared with other studies and did not change significantly after the interventions. ${ }^{4} 1030$ The voluntary nature of the surveillance system and the lack of anonymity could be an obstacle for their reporting. Barriers to incident reporting such as process complexity have been described, limiting the reliability of this type of surveillance. ${ }^{31}$ A proactive monitoring of medication errors on the ward should be performed to determine a more reliable outcome measure. The generalisation of the results of the present study to other contexts could be a matter of concern, since, to the best of our knowledge, the present study has been the first to be carried out in a paediatric setting. The findings should be applied mainly to a paediatric population, although no striking difference with other adult settings was found. Only McGillis Hall et $a l^{17}$ had previously explored the paediatric setting. They found that $9.3 \%$ of the interruptions during nursing care occurred during medications, but no improvement programme was described. In addition, the present study is the first to include such a large number of medication cycles compared with the 8-56 cycles reported elsewhere. ${ }^{14} 151823$

As for every prestudy-post study, no affirmative conclusion can be made about the cause-effect relationship of our findings. However, we speculate that the large response to the intervention observed in our study was probably due mostly to the educational sessions as reported in previous studies. ${ }^{14} 15183233$ They constituted the core of this programme, even though no single part of the bundled interventions can be described as the main element.

The improvement programme protects nurses from interruptions while they are involved in a complex process concerning patient health and safety. At the same time, it enabled nurses to postpone their responses to requests or delegate them to available colleagues without feeling guilty. The key message here is that nurses are not ignoring the patients and their families 
but protecting them from eventual harm due to interruptions. This was also reported by nurses during the debriefing meetings.

It should be underlined that not all interruptions increase the risk of error. ${ }^{34}$ An interruption may well occur, for example, due to an emerging problem. Indeed, in the study by McGillis Hall et al, ${ }^{17}$ a positive outcome was reported in $11 \%$ of the interruptions. In these situations, paediatric nurses give priority to the most relevant task, an issue that in the paediatric setting implies a 'family-centred' approach. Nurses should consider the single patients (more or less sick, more or less autonomous) and their more or less demanding families. ${ }^{35}$ Otherwise, when multitasking is inevitable, nurses perform the two tasks at the same time. ${ }^{35} 36$

\section{Limitations}

Some limitations of this study must be considered. First, the nature of the study design, because a prestudy-post study with no control could expose results to the risk of bias. In fact, although the study overall lasted 7 months, the postintervention observation was conducted just before summertime and consequently, the decrease in the clinical workload and patient turnover could have had an impact on the interruption rates. In addition, the informal exchange of information among patients' families about the programme could have led to an increased awareness of the importance of the project.

Second, as reported by Relihan et $a l^{18}$ the Hawthorne effect should also be considered. ${ }^{37}$ The awareness of being involved in a research study and under direct observation could modify participants' behaviour, confounding the real effects of the intervention on the observed participants. The research nurses limited their interactions with the observed participants and maintained an adequate distance to not disturb them.

However, measures were in place to prevent the Hawthorne effect in preintervention and postintervention observations without biasing the difference.

Third, data were collected during the busiest hours of the day, when most of the interruptions are expected and this had an impact on the type and rate of interruptions. Instead, during night shifts, interruptions caused by visitors, external noises were few. During the weekend, the decrease in the clinical workload could have also had an impact on the interruption rates.

\section{CONCLUSIONS AND IMPLICATIONS}

This study confirmed that nurses experience many interruptions during medication cycles and the improvement programme effectively reduced these interruptions. Particular attention was paid to the education sessions considered essential for a greater effectiveness of the materials used for the interventions. The authors recommend to actively involve patients and parents in the prevention and reduction of interruptions. Education regarding new organisational strategies while nurses perform medication cycles, in particular to reduce the risk of medications missing from trolleys or the medication rooms, could be proposed.

Further research is needed to confirm the effectiveness of interruption reduction programmes in the paediatric setting, particularly through a study with a control group.

\section{Author affiliations}

${ }^{1}$ Professional Development, Continuing Education and Nursing Research Service, Bambino Gesù Children's Hospital, IRCCS, Rome, Italy

Epidemiology Unit, Bambino Gesù Children's Hospital, IRCCS, Rome, Italy

${ }^{3}$ Nursing Service, Bambino Gesù Children's Hospital, IRCCS, Rome, Italy

${ }^{4}$ Master of Nursing Sciences, Tor Vergata University, Rome, Italy

${ }^{5}$ Organization and Quality Nursing Service, Bambino Gesù Children's Hospital, IRCCS, Rome, Italy

${ }^{6}$ Medical Direction, Bambino Gesù Children's Hospital, IRCCS, Rome, Italy

Acknowledgements The authors thank the patients, the families and the healthcare providers at the Bambino Gesù Children's Hospital who embraced the instructions of the improvement programme; the nurses who accepted the programme and changed their professional behaviours; I. Ciaralli, L. Cirulli, M. D’Agostino, G. Manca, F. Pontarelli, A. Portanova, A. Querciati, T. Renzetti, S. Timpani, Departmental Nurses Managers and the unit nurses managers of the hospital who played an active role in the implementation of this programme; the School of Nursing of Tor Vergata University of Rome for the collaboration; and Dott. Theresa Pape, the author of the MADOS observation sheet who provided permission for its adaptation.

Collaborators Alert System Study Group: Ilaria Campagna (Pediatric RN, Student at Master of Nursing Sciences, Tor Vergata University, Rome, Italy), Martina Di Carlo (RN, Research Fellow, Bambino Gesù Children's Hospital, IRCCS, Rome, Italy), Ilaria Franconi (RN, Research Fellow, Bambino Gesù Children's Hospital, IRCCS, Rome, Italy), Stephanie Lapadula (Pediatric RN, Student at Master of Nursing Sciences, Tor Vergata University, Rome, Italy), Patrizia Paolella (RN, Bambino Gesù Children's Hospital, IRCCS, Rome, Italy), Luisa Russo (RN, Student at Master of Nursing Sciences, Tor Vergata University, Rome, Italy).

Contributors ID planned the study, coordinated the implementation programme, helped in the translation procedure of instrument for data collection, supervised data collection and analysis, drafted and revised manuscript; MF helped planning the study, was primarily responsible for conducting the data collection, participated in data analysis and drafted manuscript; VDC helped planning the study, helped in the translation procedure of instrument for data collection, analysed data and revised manuscript; ET helped planning the study, collaborated in the implementation programme, revised the instrument for data collection and helped revising manuscript; RM participated in data collection and data analysis, drafted and revised the manuscript; NB helped in planning the study, collaborated in the implementation programme and helped in revising manuscript; MLCDA contributed in data collection and analysis of medication errors; AF helped in planning the study, participated in data collection, drafted the manuscript; $O G$ helped in the translation procedure of tool for data collection, and revised the manuscript; MP helped in planning the study, collaborated in the implementation programme, helped in revising the manuscript; MR conceived the study, supervised the implementation programme and revised the manuscript. All authors reviewed and approved the final version of the manuscript. Alert System Research Group: IC, MDC, IF, SL, PP and LR participated in data collection and imputation.

Funding This research received no specific grant from any funding agency in the public, commercial or not-for-profit sectors.

Competing interests None declared.

Ethics approval Ethics Committee of Bambino Gesù Children's Hospital (Italy). Provenance and peer review Not commissioned; externally peer reviewed.

Data sharing statement No additional data are available. 
Open Access This is an Open Access article distributed in accordance with the Creative Commons Attribution Non Commercial (CC BY-NC 4.0) license, which permits others to distribute, remix, adapt, build upon this work noncommercially, and license their derivative works on different terms, provided the original work is properly cited and the use is non-commercial. See: http:// creativecommons.org/licenses/by-nc/4.0/

\section{REFERENCES}

1. Moyen E, Camire E, Stelfox HT. Clinical Review: medication errors in critical care. Crit Care 2008;12:208.

2. Aronson J. Medication errors: what they are, how they happen and how to avoid them. QJM 2009;102:513-21.

3. Institute of Medicine. Preventing medication errors. Washington, DC: National Academy Press, 2007.

4. Kaushal R, Bates D, Landrigan C, et al. Medication errors and adverse drug events in pediatric inpatient. JAMA 2001;285:2114-20.

5. Walsh K, Kaushal R, Chessare J. How to avoid pediatric medication errors: a user's guide to the literature. Arch Dis Child 2005;90:698-702.

6. Murphy $M$, While A. Medication administration practices among children's nurses: a survey. Br J Nurs 2012;21:928-33.

7. Stratton KM, Blegen MA, Peppe G, et al. Reporting medication errors by pediatric nurses. J Pediatr Nurs 2004;19:385-92.

8. Armitage $\mathrm{G}$, Knapman $\mathrm{H}$. Adverse events in drug administration: a literature review. J Nurs Manag 2003;11:130-40.

9. Fry M, Dacey C. Factors contributing to incidence in medicine administration. Part 2. Br J Nurs 2007;16:678-81.

10. Sears K, O'Brien-Pallas L, Stevens B, et al. The relationship between the nursing work environment and the occurrence of reported pediatric medication administration errors: a pan Canadian study. J Pediatr Nur 2013;28:351-6.

11. Westbrook J, Woods A, Rob MI, et al. Association of interruptions with an increased risk and severity of medication administration errors. Arch Intern Med 2010;170:683-90.

12. Biron AD, Loiselle CG, Lavoie-Tremblay M. Work interruptions and their contribution to medication administration errors: an evidence review. Worldviews Evid Based Nurs 2009;6:70-86.

13. Dante A, Andrigo I, Barone F, et al. Occurence and duration of interruptions during nurses' work in surgical wards. J Nurs Care Qual 2015;31:174-82.

14. Pape TM. Applying airline safety practices to medication administration. Medsurg Nurs 2003;12:77-93.

15. Tomietto M, Sartor A, Mazzoccoli E, et al. Paradoxical effects of a hospital-based, multi intervention programme aimed at reducing medication round interruptions. J Nurs Manag 2012;20:335-43.

16. Buchini S, Quattrin R. Avoidable interruptions during drug administration in an intensive rehabilitation ward: improvement project. J Nurs Manag 2012;20:326-34.

17. McGillis Hall L, Pedersen C, Hubley $P$, et al. Interruptions and pediatric patient safety. J Pediatr Nurs 2010;25:167-75.

18. Relihan E, O'Brien V, O'Hara S, et al. The impact of a set of interventions to reduce interruptions and distractions to nurses during medication administration. Qual Saf Health Care 2010;19: e52.

19. Nguyen EE, Connolly PM, Wong V. Medication safety initiative in reducing medication errors. J Nurs Care Qual 2010;25:224-30.

20. Conrad C, Fields W, McNamara T, et al. Medication room madness: calming the chaos. J Nurs Care Qual 2010;25:137-44.

21. Freeman R, McKee S, Lee-Lehner B, et al. Reducing interruptions to improve medication safety. J Nurs Care Qual 2013;28:176-85.

22. Kliger J, Singer S, Hoffman F, et al. Spreading a medication administration intervention organizationwide in six hospitals. Jt Comm J Qual Patient Saf 2012;38:51-60.

23. Anthony $\mathrm{K}$, Wiencek $\mathrm{C}$, Bauer $\mathrm{C}$, et al. No interruptions please: impact of a no interruption zone in medication safety in intensive care units. Crit Care Nurse 2010;30:21-9.

24. Raban MW, Westbrook Jl. Are interventions to reduce interruptions and errors during medication administration effective? A systematic review. BMJ Qual Saf 2014;23:414-21.

25. Ciofi degli Atti M, Paolini V, Cavallin M, et al. Proactive evaluation of clinical risk: a FMECA analysis in pediatric chemotherapy. Ann Ig 2013;25:1-7.

26. Pape TM. The effect of nurses' use of a focused protocol to reduce distractions during medication administration [PhD thesis]. Houston: Texas Woman's University, 2002.

27. Craig P, Dieppe P, Macintyre S, et al. Developing and evaluating complex interventions: the new Medical Research Council guidance. Int J Nurs Stud 2013;50:587-92.

28. Palese A, Ferro M. 'I am administering medication-please do not interrupt me': red tabards preventing interruptions as perceived by surgical patients. J Patient Saf 2015. Published Online First: 7 April 2015.

29. Kliger J, Blegen MA, Gootee D. Empowering frontline nurses: a structured intervention enables nurses to improve medication administration accuracy. Jt Comm J Qual Patient Saf 2009;35:604-12.

30. Gonzales K. Medication administration errors and the pediatric population: a systematic search of the literature. J Pediatr Nurs 2010;25:555-65.

31. Evans SM, Berry JG, Smith BJ, et al. Attitudes and barriers to incident reporting: a collaborative hospital study. Qual Saf Health Care 2006;15:39-43.

32. Capasso V, Johnson M. Improving the medicine administration process by reducing interruptions. J Health Manag 2012:57:384-90.

33. Pape TM. The effect of five-part intervention to decrease omitted medication. Nurs Forum 2013;48:211-22.

34. Grundgeiger T, Sanderson PM. Interruptions in healthcare: theoretical views. Int J Med Inform 2009;78:293-307.

35. Colligan L, Bass EJ. Interruption handling strategies during paediatric medication administration. BMJ Qual Saf 2012;21: 912-7.

36. Westbrook Jl. Interruptions and multi-tasking moving the research agenda in new directions. BMJ Qual Saf 2014;23:877-9.

37. Polit DF, Beck CT. Nursing research: generating and assessing evidence for nursing practice. Philadelphia, PA: Lippincott Williams \& Wilkins, 2012:729. 